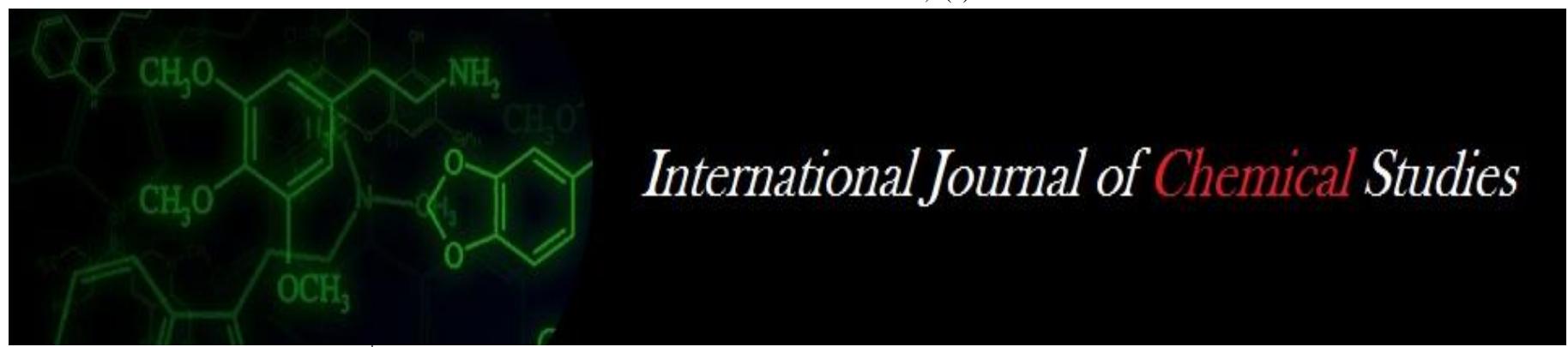

P-ISSN: 2349-8528

E-ISSN: 2321-4902

www.chemijournal.com

IJCS 2020; 8(2): 764-770

(C) 2020 IJCS

Received: 09-01-2020

Accepted: 12-02-2020

\section{Kamal Purohit}

Assistant Professor, Collage of

Veterinary and Animal Science,

Navania, Vallabhnagar,

Udaipur, Rajasthan, India

Sudeep Solanki

Assistant Professor, Collage of

Veterinary and Animal Science,

Navania, Vallabhnagar,

Udaipur, Rajasthan, India

Goverdhan Singh

Assistant Professor, Collage of

Veterinary and Animal Science,

Navania, Vallabhnagar,

Udaipur, Rajasthan, India

Shanmuga Sundaram Nagarajan High Security Animal Disease Laboratory, Principal Scientist, Indian Veterinary Research Institute, Anand Nagar, Bhopal, Madhya Pradesh, India

\section{Corresponding Author:}

Kamal Purohit

Assistant professor, Collage of

Veterinary and Animal Science,

Navania, Vallabhnagar,

Udaipur, Rajasthan, India

\section{Assessment of experimental pathogenicity of avian influenza virus $\mathrm{H9N2}$ isolates by intravenous pathogenicity index (IVPI) test and histopathology}

\author{
Kamal Purohit, Sudeep Solanki, Goverdhan Singh and Shanmuga \\ Sundaram Nagarajan
}

DOI: https://doi.org/10.22271/chemi.2020.v8.i21.8860

\begin{abstract}
A total of 1,423 number of tissue samples received from various parts of India were processed for virus isolation in chicken embryos of 9-11 d old as a part of programme to monitor Avian Influenza Virus (AIV) infection in Indian poultry population and a total number of three samples were positive by HA test and the titre of the virus isolates ranged from 1:8 to 1:64. The virus isolates had been subjected to HI test with the reference positive serum imported from NVSL, USA for various subtypes. The virus isolates gave a $\mathrm{HI}$ titre of 1:32 with $\mathrm{H} 9$ subtype specific reference positive serum indicating that the virus isolates were influenza A H9 subtype. One of the isolates (accession no. 3722/04) was subjected to neuraminidase assay and the virus was found by $\mathrm{N} 2$ subtype and also virus sub typing was done by RTPCR for further confirmation. The influenza H9N2 virus isolates (accession no. 2543/04, 2544/04, $2317 / 04,2424 / 04$, and 3722/04) were used in the intravenous pathogenicity index test. In the present study no, clinical signs and/or gross lesions in experimentally inoculated chickens were observed. All the five isolates studied were found to be non-pathogenic according to the European Union definition. The organs collected from the experimental chickens did not show significant lesions, on histopathological examination, except for some minor changes in some of the organs. Immunofluorescence test was used to study the tissue tropism of avian influenza viruses' isolates experimentally infected in chickens. The antigen was detected only in the brain and trachea of the chickens experimentally infected with the isolates having accession no. 2543/04 and intestine of chickens experimentally infected with the isolate having accession number 2544/04. Avian influenza virus re-isolation from experimentally infected chickens was attempted in 9-11 d old embryonated chicken eggs. Virus could be re-isolated from some organs, three groups infected with the isolates with accession numbers 2543/04, 2544/04 and 2317/04. Thus, the present work was envisaged to fill in the gap formed by this lack of information on avian influenza in India.
\end{abstract}

Keywords: H9N2 virus influenza a virus's clinical signs

\section{Introduction}

Influenza virus has been isolated from variety of animals, including humans, pigs, horses, sea mammals, and birds ${ }^{[40,41]}$. Influenza viruses are classified as A, B, and C types based on antigenic differences in their nucleoprotein (NP) and matrix (M1) protein. Avian influenza is caused by type A influenza virus, a member of the family Orthomyxoviridae ${ }^{[18,21]}$. The natural reservoirs of Influenza A viruses are the aquatic wild birds of the world, in which the viruses appear to be in evolutionary stasis (in equilibrium with their natural host and cause no disease). Periodically, the virus is transmitted to other hosts, including mammals, and cause transitory infections and occasionally deaths ${ }^{[24,41]}$. Type A avian influenza viruses are further divided into subtypes on the basis of two surface glycoproteins - hemagglutinin (HA) and neuraminidase (NA), ${ }^{[4,11]}$. Sixteen HA (H1-H16) and nine NA (N1-N9) subtypes have been identified ${ }^{[12,26,33]}$. Based on the pathogenicity of AIV in domestic poultry, the viruses are subclassified in to two pathotypes of highly pathogenic avian influenza (HPAI) and non-highly pathogenic avian influenza (nHPAI) viruses, including mild pathogenic, low pathogenic and non-pathogenic AIV ${ }^{[37]}$. All the 16 HA subtypes of influenza viruses are viruses ${ }^{[12,42]}$. Among 16 HA subtypes only H5 and H7 are highly virulent to poultry ${ }^{[1,12]}$. 
Avian influenza infection ranges from a mild or even asymptomatic infection to acute, fatal disease ${ }^{[3]}$. The typical signs and symptoms manifested by poultry infected with highly pathogenic avian influenza viruses include decreased egg production, respiratory signs, rales, excessive lacrimation, sinusitis, cyanosis of unfeathered skin (specially the combs and wattles), oedema of the head and face and nervous system disorders. The number of presenting features depends on the species and the age of the bird, the strain of virus and accompanying bacterial infection ${ }^{[11,39]}$. The gross and histological lesions in chickens inoculated with highly pathogenic virus are quite similar but do show some variations [11, 25] and include swelling of micro vascular endothelium, systemic congestion, multifocal haemorrhages, perivascular mononuclear cell infiltration and thrombosis. The viruses replicate efficiently in the vascular endothelium and perivascular parenchymatous cell, a property that appears important for viral dissemination and systemic infection ${ }^{[20,36]}$. Seeing the genetic heterogeneity of recent nonhuman H9N2 isolates, it is important to examine H9N2 isolates from avian hosts in addition to those obtained from humans ${ }^{[13,32]}$. In recent years, outbreaks in poultry due to viruses of $\mathrm{H} 9$ subtypes, especially H9N2 have been widespread ${ }^{[13]}$. Crossing the species barrier to mammals highlights the pandemic potential of H9N2 virus ${ }^{[32]}$. The outbreaks due to H9N2 subtypes have been reported in Germany, Italy, Ireland, South Africa, USA, Korea, China, Middle East, Saudi Arabia and Pakistan during the latter half of last decade ${ }^{[2,7]}$.

The key to influenza pandemic preparedness is good surveillance for influenza viruses ${ }^{[14]}$. Today, modern laboratory techniques, clinical and epidemiologic knowledge, and global communication provide the opportunity to monitor the evolving outbreak and act on it ${ }^{[17]}$. Thus, continuous screening of the samples from Indian poultry and identification of the subtype of the virus isolated is imperative. Also, the pathogenic potential of the isolated subtypes remains to be recognized.

The poultry sector in India has undergone a paradigm shift in structure and operation from a mere backyard activity into a major commercial industry over a period of four decades. India is the third-largest egg producer and the fourth-largest chicken producer. Introduction on virus cause severe economic loss to poultry industry. Department of Animal Husbandry, Dairying and Fisheries, Ministry of Agriculture, Government of India initiated a programme AIV infection infection in Indian Poultry population in collaboration with HSADL, IVRI, Indian Council of Agriculture Research, which is a National Referral facility.

\section{Materials and Methods \\ Samples and history}

A total of 1,423 number of tissue samples were received from various parts of the country and screened for the presence of AIV infection. The tissue samples usually included intestine, trachea, liver, kidney, spleen, proventriculus, brain, heart, and pancreas and egg peritonitic fluid. The samples were collected from flocks with a history of mild respiratory illness and drop in egg production. and history of vaccination against Marek's disease.

\section{Virus isolation}

Virus isolation was carried out in 9-11 days old SPF embryonated chicken eggs as per the standard protocol OIE ${ }^{\text {[31] }}$. Briefly, triturated tissue samples treated with $2 \times$ antibiotic and antimycotic solution (Sigma, USA) for $30 \mathrm{~min}$ at $37{ }^{\circ} \mathrm{C}$ and clarified by centrifugation at $5000 \mathrm{rpm}$ for $10 \mathrm{~min}$ were inoculated through allantoic and amniotic routes. The amnioallantoic fluid was harvested after incubation at $37{ }^{\circ} \mathrm{C}$ for $72-$ $96 \mathrm{~h}$ and clarified by centrifugation at $1500 \times g$ for $15 \mathrm{~min}$ at $4{ }^{\circ} \mathrm{C}$. HA test negative samples were given two more passages and tested again before being declared negative for AIV isolation.

\section{HA subtyping}

The HA subtyping for each of the isolates was carried out as per the standard protocol described by OIE ${ }^{[31]}$. Briefly, HA test was performed with $25 \mu \mathrm{l}$ of infected CAF to calculate 4 HA units of the isolates. The haemagglutination inhibition (HI) test was performed using subtype specific reference antisera obtained from Dr. B. Panigrahy, NVSL, USA. Since the reference antisera for the H16 subtype was not supplied by the reference laboratory, screening for H16 subtype was not done. The HI assay was performed in V-bottom 96-well microtiter plates (Laxbro, India) using 1\% chicken RBC. RNA was extracted from chorio allantoic fluid (CAF) samples using QiaAmp viral RNA mini kit (Qiagen Inc., USA) following manufacturer's instructions. The cDNA was synthesized using universal 12-mer Uni12 primer 5'-AGCAAAAGCAGG-3' AMV-RT (RevertAid H Minus First Strand cDNA Synthesis Kit, Fermentas, USA) and PCR was performed as described ${ }^{[23]}$. with minor modifications.

\section{NA subtyping}

The NA subtyping was done by neuraminidase inhibition (NAI) assay as per the standard protocol ${ }^{[43]}$. A dilution of the isolate that gave $0.5 \mathrm{OD}$ with neuraminidase assay was used in the NAI test. The NA subtype was determined using the subtype specific reference sera for N1-N9 subtypes obtained from VLA, Surrey, UK and antigens from NVSL, USA. Neutralization of the virus by subtype specific antiserum resulting in non-development of pink color indicated the NA subtype of the isolate.

\section{Intravenous Pathogenicity Index (Ivpi) Test}

Five H9N2 isolates (accession no. 2424/04, 2543/04, 2544/04, $2317 / 04$ and $3722 / 04$ ) isolated, were subjected to intravenous pathogenicity index (IVPI) test in chickens

\section{Experimental Design}

To determine the pathogenicity of the five virus isolates, the IVPI test was carried out according to the recommendation of the Office International Des Epizootics ${ }^{[30]}$. The IVPI test was conducted in three phases using five different virus isolates as shown in Table-1 and in each phase a control group was also maintained.

Table 1: Different Phases of IVPI Test

\begin{tabular}{|c|c|}
\hline Laboratory accession no. & HA titer \\
\hline \multicolumn{2}{|c|}{ Phase I } \\
\hline $2543 / 04$ & $1: 128$ \\
\hline $2544 / 04$ & $1: 16$ \\
\hline Phase II & $1: 32$ \\
\hline $2317 / 04$ & $1: 16$ \\
\hline $2424 / 04$ & $1: 64$ \\
\hline Phase III
\end{tabular}

Four to six-week-old specific-pathogen-free chickens were obtained from government poultry farm, Bhopal, that were tested for the absence of antibodies to avian influenza viruses. 
Eight birds in each group were injected intravenously in jugular vein with $0.1 \mathrm{ml}$ per bird of inoculum prepared by diluting fresh infectious allantoic fluid having a HA titre $>16$ with sterile $1 \mathrm{X}$ PBS and control groups were inoculated with $1 \mathrm{X}$ PBS. Birds where examined daily for $10 \mathrm{~d}$ and scored 0 if normal, 1 if sick, 2 if very sick, and 3 if dead (the judgment of sick and severely sick birds is a subjective clinical assessment. Normally, 'sick' birds would show one of the following signs and 'severely sick' more than one of the following signs: respiratory involvement, depression, diarrhoea, cyanosis of the exposed skin or wattles, edema of the face and / head, nervous signs. Dead individual birds must be scored as 3 at each of the remaining daily observations after death). Examine the birds for clinical signs at intervals of $24 \mathrm{~h}$ over a 10-day period. At the end of 10 day of the observation period, the sum of the observations in each category was totalled and divided by the total number of observations. Kill any bird unable to feed or drink and record as dead at the following day's observation time.

\section{Collection of blood samples}

After 10 day of virus inoculation blood samples were collected from both inoculated test group and uninoculated control group. Blood samples where tested for the presence of influenza A virus antibody by AGID test.

\section{Collection of tissue samples}

Tissue samples were collected from euthanatized or naturally dead chickens in each inoculated group on 10 day post inoculated. Tissue samples were also collected daily from any other chickens that died during the experiment. Tissue samples were also collected from each uninoculated control chickens. The following tissues samples were collected: brain, trachea, lung, spleen, heart, kidney, pancreas, liver, proventriculus and intestine A part of tissue sample was fixed in $10 \%$ neutral buffered formalin solution and was later used for histopathological studies. Another part was cryopreserved at $-40{ }^{\circ} \mathrm{C}$ and was later used for IFAT.

\section{Histopathology}

Tissue samples were routinely processed to paraffin wax blocks, and sections where stained with hematoxylin and eosin ( $\mathrm{H}$ and $\mathrm{E}$ ) for light microscopic examination.

\section{Immunofluorescent test}

The immunofluorescent test was performed on $5 \mu \mathrm{m}$ cryostat tissue sections for the demonstration of AIV antigen in the tissues. For the test, $5 \mu \mathrm{m}$ tissue sections were mounted on clean RNase free glass slides. The tissue sections were fixed in chilled pure acetone for $30 \mathrm{~min}$. Then sections were washed by flooding with $1 \mathrm{X}$ PBS ( $\mathrm{pH} \mathrm{7.2)} \mathrm{for} 10 \mathrm{~min}$. After proper wash, sections were flooded with 1:200 diluted AIV polyclonal antibody and incubated, for $1 \mathrm{~h}$ at $37^{\circ} \mathrm{C}$. Sections were again washed once with $1 \mathrm{X}$ PBS for $10 \mathrm{~min}$ and then incubated with 1:350 anti-chicken IgG FITC conjugate for 1/2 $\mathrm{h}$ in dark room. Again, give a proper wash for $10 \mathrm{~min}$. Finally, the slides were mounted in $50 \%$ glycerol and viewed in a fluorescent microscope for fluorescence, for the presence of
AIV antigen inside the tissues.

\section{Results}

A total of 1,423 number of tissue samples were received from various parts of the country. The tissue samples were processed for virus isolation in avian influenza virus antibody negative chicken embryos of 9-11 d old after dilution of 1:10 with $1 \mathrm{X}$ PBS. The allantoic fluid from the infected embryos was harvested at $72 \mathrm{~h}$ after infection.

\section{Subtyping of influenza virus HI Test}

The virus isolates that gave HA titers had been subjected to HI test with the reference positive serum imported from NVSL, USA for various subtypes viz. H5, H7 and $\mathrm{H} 9$ subtypes. The virus isolates showed no HI with the H5 and H7 subtype specific reference positive serum but gave a HI titer of 1:32 with $\mathrm{H} 9$ subtype specific reference positive serum indicating that the virus isolates were influenza A H9 subtype. The reference H9 subtype specific antigen gave an $\mathrm{HI}$ titer of 1:64. The virus isolates were also subjected to HI test with NDV hyperimmune serum and all samples gave negative result indicating that the isolates were free of ND virus contamination.

\section{Neuraminidase inhibition assay}

One of the isolates (accession no. 3722/04) was subjected to neuraminidase assay. For this, various dilutions of the virus viz. neat, $10-0.5,10-1.0,10-1.5,10-2.0$ and 10-2.5 were used. The OD values for each dilution of the virus were measured in the spectrophotometer at a wavelength of $549 \mathrm{~nm}$.Serial dilutions of the reference serum for all the nine subtypes N1N9 were made as per the standard procedure. The virus showed inhibition of the neuraminidase activity up to the dilution of 10-1.0 as indicated by white color of the reaction mixture when compared with other subtypes against $\mathrm{N} 2$ subtype antiserum. This indicated that the virus belongs to N2 subtype.

\section{Intravenous pathogenicity index test Passaging of virus isolates in embryonated chicken eggs} The influenza H9N2 virus isolates (accession no. 2543/04, 2544/04, 2317/04, 2424/04, and 3722/04) isolated earlier were passaged in 9-11 d old embryonated chicken eggs after neutralizing 1:10 dilution with NDV hyperimmune serum. The allantoic fluid from the infected embryos was harvested at $72 \mathrm{~h}$ after infection and tested by HA test for the presence of the virus. The virus isolates were diluted in the ratio of $1: 10$ with $1 \mathrm{X}$ PBS as per the recommended procedures of WHO/OIE. The test was conducted in three phases and the results are shown in Tables 2; 3, and 4. Two birds inoculated with the virus isolate 2543/04 and 2544/04 showed mild respiratory distress on the 6 and 4 day, respectively. The birds recovered next day and remained normal throughout the remaining period of study. The birds were observed for a period of 10 day and all the surviving birds were sacrificed and observed for gross lesions if any. Both the control and inoculated birds did not show any clinical signs and lesions.

Phase I:

\begin{tabular}{|c|c|c|c|c|c|c|c|c|c|c|c|c|}
\hline Clinical Signs & D1 & D2 & D3 & D4 & 05 & 96 & & & D9 & D1 & Total| & Score \\
\hline \multicolumn{13}{|c|}{ Virus 2543/04 } \\
\hline Normal & 8 & 8 & 8 & 8 & 8 & 8 & 8 & 8 & 8 & 8 & $80 \times 0$ & $=0$ \\
\hline Sick & 0 & 0 & 0 & 0 & 0 & 1 & 0 & 0 & 0 & 0 & $1 \times 1$ & $=1$ \\
\hline Paralyzed & 0 & 0 & 0 & 0 & 0 & 0 & 0 & 0 & 0 & 0 & $0 \times 2$ & $=0$ \\
\hline
\end{tabular}




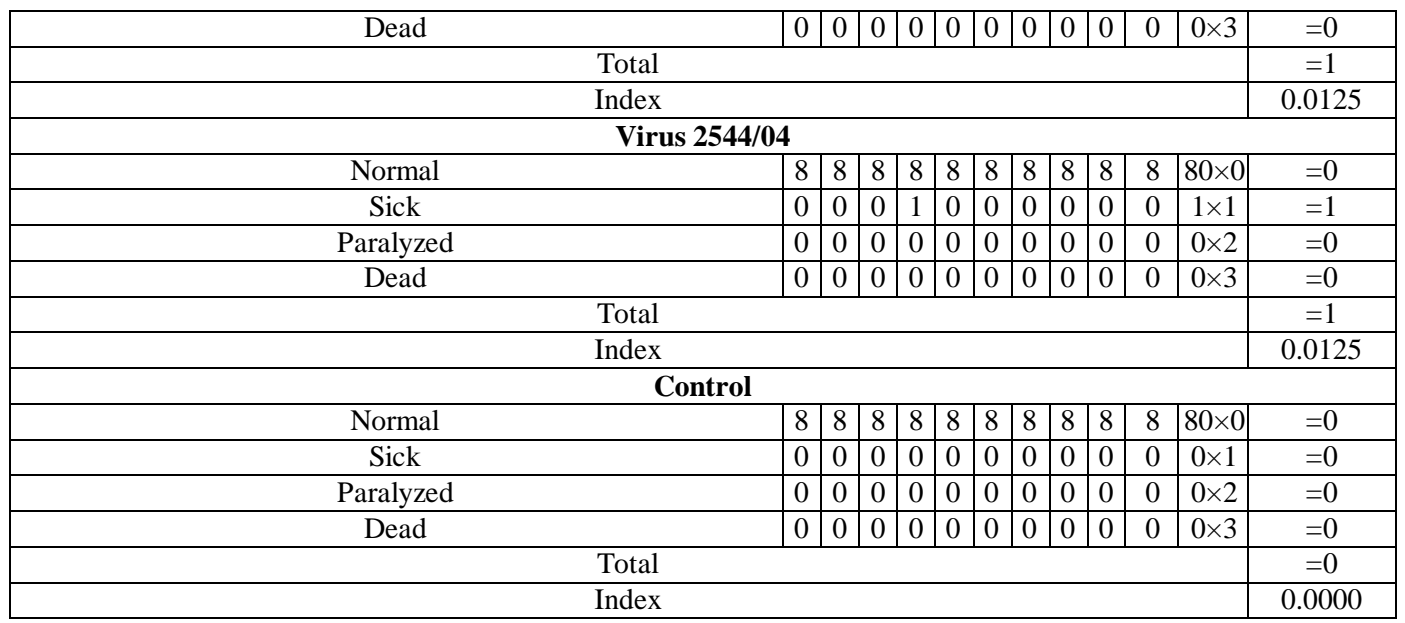

The index is calculated as the mean score per bird per observation. [Non-pathogenic 0 (range 0-1.0)], D-Day
Table 2 Intravenous Pathogenicity Index Test Observation for Phase I

Phase II:

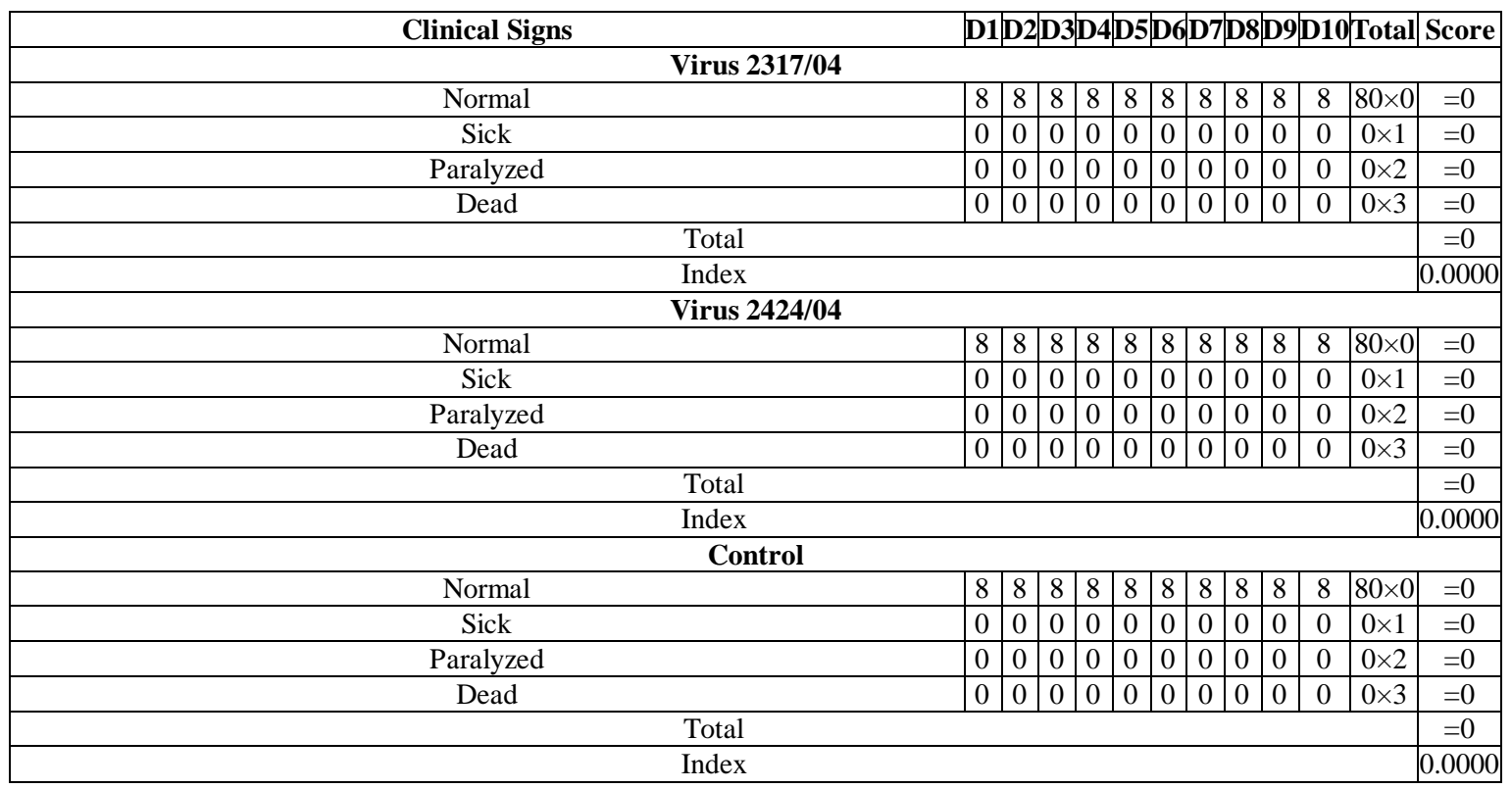

The index is calculated as the mean score per bird per observation. [Non-pathogenic 0 (range 0-1.0)] in vitro, D-Day
Table 3 Intravenous Pathogenicity Index Test Observation for Phase II

Phase III:

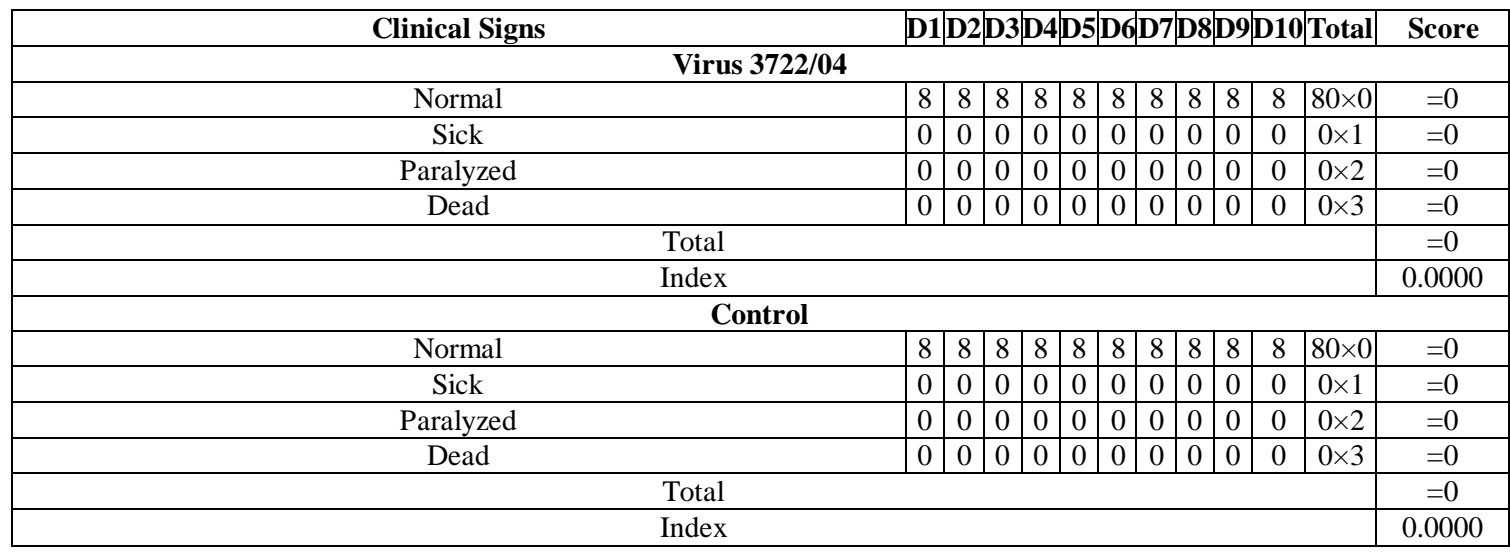

The index is calculated as the mean score per bird per observation. [Non-pathogenic 0 (range 0-1.0)], D-Day Table 4. Intravenous Pathogenicity Index Test Observation for Phase III

\section{Serology}

Avian influenza virus group specific precipitating antibodies where present in the serum samples collected from all the five group, on fourth and tenth day, which where inoculated with 
the virus. There was no evidence of precipitating antibodies against AIV.

\section{Histopathology}

On histopathological examination no significant lesions characteristic of avian influenza could be observed in any of the target organs

\section{Immunofluorescence Test}

For detection immunofluorescent antigen of avian influenza virus brain, trachea, lung, heart, proventriculus, liver, spleen, kidney, and intestine of all test groups were used. Except in two birds inoculated with the virus isolate no. 2543/04 and one bird inoculated with the virus isolate no. 2544/04 immunofluorescence antigen could not be detected in any test group Table 5.

Table 5: Results of Immunofluorescence Test

\begin{tabular}{|c|c|c|c|c|c|c|c|c|}
\hline \multirow{2}{*}{ Organs } & \multicolumn{3}{|c|}{ Phase I } & \multicolumn{3}{c|}{ Phase II } & \multicolumn{2}{c|}{ Phase III } \\
\cline { 2 - 8 } & $\mathbf{2 5 4 3 / 0 4}$ & $\mathbf{2 5 4 4 / 0 4}$ & Control & $\mathbf{2 3 1 7 / 0 4}$ & $\mathbf{2 4 2 4 / 0 4}$ & Control & $\mathbf{3 7 2 2 / 0 4}$ & Control \\
\hline Brain & Positive (1 bird) & Negative & Negative & Negative & Negative & Negative & Negative & Negative \\
\hline Trachea & Positive (1 bird) & Negative & Negative & Negative & Negative & Negative & Negative & Negative \\
\hline Lungs & Negative & Negative & Negative & Negative & Negative & Negative & Negative & Negative \\
\hline Heart & Negative & Negative & Negative & Negative & Negative & Negative & Negative & Negative \\
\hline Proventriculus & Negative & Negative & Negative & Negative & Negative & Negative & Negative & Negative \\
\hline Liver & Negative & Negative & Negative & Negative & Negative & Negative & Negative & Negative \\
\hline Spleen & Negative & Negative & Negative & Negative & Negative & Negative & Negative & Negative \\
\hline Kidney & Negative & Negative & Negative & Negative & Negative & Negative & Negative & Negative \\
\hline Intestine & Negative & Positive $(1$ bird) & Negative & Negative & Negative & Negative & Negative & Negative \\
\hline
\end{tabular}

\section{Virus reisolation}

Avian influenza virus reisolation was attempted from the both infected and control groups from liver, kidney, proventriculus, brain, trachea, spleen, intestine and heart which were collected on 10 day of post infection. The inoculums prepared from these organs were used for inoculation of embryos. Reisolation of virus could be achieved from three groups (of isolates with accession no. 2543/04, 2544/04, and 2317/04) and not from two other groups (of isolates with accession no. 2424/04, and 3722/04) and control group Table 6.

Table 6: Reisolation of Virus in Experimental Studies

\begin{tabular}{|c|c|c|c|c|c|c|c|c|}
\hline Brain & Trachea & Lung & Heart & Proventriculus & Liver & Spleen & Kidney & Intestine \\
\hline \multicolumn{9}{|c|}{ Phase I } \\
\hline \multicolumn{9}{|c|}{$2543 / 04$} \\
\hline+ & + & + & + & + & + & - & + & + \\
\hline \multicolumn{9}{|c|}{$2544 / 04$} \\
\hline+ & - & + & + & + & + & - & + & + \\
\hline \multicolumn{9}{|c|}{ Control } \\
\hline- & - & - & - & - & - & - & - & - \\
\hline \multicolumn{9}{|c|}{ Phase II } \\
\hline \multicolumn{9}{|c|}{$2317 / 04$} \\
\hline+ & + & + & + & + & + & - & - & + \\
\hline \multicolumn{9}{|c|}{$2424 / 04$} \\
\hline- & - & - & - & - & - & - & - & - \\
\hline \multicolumn{9}{|c|}{ Control } \\
\hline- & - & - & - & - & - & - & - & - \\
\hline \multicolumn{9}{|c|}{ Phase III } \\
\hline \multicolumn{9}{|c|}{$3722 / 04$} \\
\hline- & - & - & - & - & - & - & - & - \\
\hline \multicolumn{9}{|c|}{ Control } \\
\hline- & - & - & - & - & - & - & - & - \\
\hline
\end{tabular}

\section{Discussion}

A total of 1,423 number of tissue samples received from various parts of the country were processed for virus isolation in avian influenza virus antibody negative chicken embryos of 9-11 d. All the isolates of avian influenza virus grew readily in 9-11 day old embryonated chicken eggs, as the avian influenza viruses are very stable in allantoic fluid because the presence of protein protects the viruses, making this the most universally used method for isolation of avian influenza viruses ${ }^{[11]}$. The allantoic fluid from the infected embryos was harvested at $72 \mathrm{~h}$ after infection and HA titer was determined as per the procedure detailed ${ }^{[43]}$.

To determine the antigenic subtype based on the immunologic specificities of their surface glycoprotein antigens, HAs and
NAs ${ }^{[11,16]}$. Determination of the subtypes of influenza A virus isolates are the first steps in the characterization of influenza viruses ${ }^{[45]}$. The HA subtype is identified in the HAI test ${ }^{[10]}$ using a panel of antisera prepared against the 15 distinct HAs $[11,40]$. However recently a new HA subtype numbered 16 has also been identified ${ }^{[12]}$. Typing is facilitated by using antisera against the isolated HA; this helps avoid steric inhibition due to antibodies against the NA.

The intravenous pathogenicity index test was conducted for five different isolates in three different phases. The experimental birds were observed for a period of $10 \mathrm{~d}$ and all the surviving birds were sacrificed, as proposed ${ }^{[43]}$. Avian influenza infections in domestic poultry come out within different clinical syndromes ${ }^{[44]}$. The occurrence of the disease 
syndrome or the degree of severity of the disease produced in domestic poultry depends on multiple factors like the pathogenicity of the virus, care and nutrition of birds, age of the birds, route of infection, and existence of secondary infections ${ }^{[8,38]}$. Severity of the disease also depends on whether the infection was natural or experimental as some AIV stains caused sever systemic infections and high mortality in natural conditions, ${ }^{[9,27,29]}$. The virus produced in mild disease in the experimental infections ${ }^{[4,15,19,35]}$. In the present study, mortality was not observed during the 10-d observation period after intravenous inoculation with five isolates. Even the birds did not show clinical signs and/or gross lesions. No death occurred in control birds. The pathogenicity indices of the isolates with accession numbers 2543/04 and 2544/04, studied in the Phase I, were found to be 0.0125 . All the other three isolates gave scores of 0.00 . Thus, all the five isolates studied were found to be non-pathogenic according to the European Union definition ${ }^{[43]}$.

The blood samples collected from experimental birds where tested for the presence of influenza A virus antibody by AGID test. The control group did not show any serologic evidence of AIV infection. The avian influenza virus group specific precipitating antibodies were present in the serum samples collected from all the five inoculated groups, on four and ten days. Similar observations were also recorded by ${ }^{[25]}$.

Variations in the pathogenicity and transmissibility of influenza viruses for different hosts have frequently caused problems in diagnosis, definition and the understanding of the influenza infection in poultry ${ }^{[6]}$. Most of the differences reported in field infections of the same species of birds with ostensibly the same virus have been as a result of exacerbation due to other organisms or adverse conditions [28] and in laboratory infections influenza viruses have tended to be either overtly pathogenic or of low pathogenicity for chickens and turkeys ${ }^{[4]}$.

The organs collected from the experimental chickens did not present significant lesions, on histopathological examination, except for mild congestion in lung with one isolate (with accession numbers 2543/04) [25] did not obtain any histopathological lesion in experimental inoculation studies of a mild pathogenic influenza virus strain in chickens. The strains used in this study were found to be non-pathogenic and thus, might have failed to produce any substantial histopathological lesions as there might have been lack of persistence of the virus in the tissues ${ }^{[25]}$.

The immunofluorescence test developed by ${ }^{[5]}$ following the 1985 HPAI outbreak in Victoria, Australia, using a small number of tissues from experimentally infected chickens. This test was subsequently used to provide a rapid diagnosis in the 1992, 1994, 1997 and $2002^{\text {[34] }}$. In the present study immunofluorescence test was used to study the tissue tropism of avian influenza viruses' isolates experimentally infected in chickens. Liver, kidney, proventriculus, brain, trachea, spleen, intestine and heart, from infected and control groups were collected and processed for immunofluorescence test. The antigen was detected only in the brain and trachea of the chicken group experimentally infected by the isolates with accession numbers 2543/04 and intestine of the chicken group experimentally infected by the isolates with accession numbers 2544/04. Remaining organs of the chicken groups experimentally infected by these two isolates as well as all the organs of the chicken groups experimentally infected by the other three isolates lacked immunofluorescence. [25] had reported similar findings where one of the strain of avian influenza virus experimentally inoculated into chickens was not detected by immunoperoxidase staining though showed the presence of AIV-specific AGP antibodies in serum. Immunofluorescence test identifies simply the presence of the influenza A antigen in an organ that is not infected by LPAI viruses ${ }^{[34]}$. All the isolates studied in the present study were found to be non-pathogenic and thus the organs from experimentally infected birds failed, with few exceptions, to give immunofluorescence.

\section{Conclusion}

H9N2 subtypes were found to be present in the Indian poultry, and all the isolates subjected to intravenous pathogenicity index (IVPI) test were found to be nonpathogenic. The organs collected from the experimental chickens did not present significant lesions and also the Immunofluorescence test showed that the organs from experimentally infected birds failed, with few exceptions, to give immunofluorescence.

\section{Compliance with ethical standards}

The study was approved by the appropriate institutional ethics procedures.

\section{Conflict of interest}

1. The authors declare that they have no conflict of interest.

\section{Acknowledgments}

All the authors of the manuscript thank and acknowledge their respective Universities and Institutes.

\section{References}

1. Alexander DJ. The Epidemiology and control of avian influenza and Newcastle disease. J Comp. Pathol. 1995; 112:105-126.

2. Alexander DJ. A review of avian influenza in different bird species. Vet. Microbial. 2000; 74:3-13.

3. Alexander DJ, Lister SA, Jhonson MJ, Randell CJ, Thomas PJ. An outbreak of highly pathogenic avian influenza in turkey in Great Britain in 1991. Vet. Rec. 1993; 132:535-536.

4. Alexander DJ, Parsons G, Manvel RJ. Experimental assessment of the pathogenicity of eight avian influenza A viruses of $\mathrm{H} 5$ subtype for chickens, turkeys, ducks and quails. Avian Pathol. 1986; 15:647-662.

5. Allan GM, McNulty MS. A direct immunofluorescence test for the rapid detection of avian influenza virus antigen in tissue impression smears. Avian Pathol. 1985; 14:449-446.

6. Bankowski RA. Introduction and objectives of the symposium. Proceedings of the first symposium on avian influenza, 1981. pp VII-XIV. Richmond, USA: Carter Comp. Corp, 1982.

7. Banks J, Speidel EC, Harris PA, Alexander DJ. Phylogenetic analysis of influenza A virus of $\mathrm{H} 9$ hemagglutinin subtype. Avian Pathol. 2000; 29:353-360

8. Brugh M, Beard CW. Influence of dietary calcium stress on lethality of avian influenza viruses for laying chickens. Avian Dis. 1986; 30:672-678.

9. Brugh M, Purdue ML. Emergence of highly pathogenic during selective chicken passage of the prototype mildly pathogenic chicken/Pennsylvania/83 (H5N2) influenza virus. Avian Dis. 1991; 35:824-833.

10. Centers for Disease Control. Concepts and procedures for laboratory-based influenza surveillance. Centers for 
Disease Control, United States Department of Health and Human Services, Washington, DC, 1982.

11. Easterday BC, Hanshaw VS, Halvorsen DA. Influenza. In: Diseases of poultry. Editors: Calnek, B.W., Johm Barnes, H., Beard, C.W., Reid, W.M. and Yoder, H.W. 10th ed. Iowa State University Press, Iowa, 1997, pp.583605.

12. Fouchier RAM, Munster V, Wallensten A, Bestebroer TM, Herfst S, Smith D. et al Characterization of a novel influenza a virus hemagglutinin subtype (H16) obtained from black-headed gulls. J. Virol. 2005; 79:2814-2822.

13. Guan Y, Shortridge KF, Krauss S, Webster RG. Molecular characterization of H9N2 influenza viruses: were they the donors of the internal genes of H5N1 viruses in Hong Kong? Proc. Natl. Acad. Sci. 1999; 96:9363-9369.

14. Guan Y, Shortridge KF, Krauss S, Chin PS, Dyrting KC, Ellis TM. et al H9N2 influenza viruses possessing H5N1like internal genomes continue to circulate in Poultry in Southern China. J. Virol. 2000; 74:9372-9380.

15. Halvorsan DA, Karunakaran D, Newman JA. Avian influenza in caged laying chickens. Avian Dis. 1980; 24: 288-294.

16. Hilleman MR. Realities and enigmas of human viral influenza: pathogenesis, Epidemiology and control. Vaccine. 2002; 20:3068-3087.

17. Hirst M, Astell CR, Griffith M, Coughlin SM, Moksa M, Zeng T. et al Novel avian influenza H7N3 strain outbreak, British Columbia. Emerg. Infect. Dis. 2004; 10:2192-2195.

18. Horimoto T, Kawaoka Y. Pandemic threat posed by avian influenza A viruses. Clin. Microbiol. Rev. 2001; 14:129-149.

19. Johnson DC, Maxfield BG. An occurrence of avian influenza virus infection in laying chickens. Avian Dis. 1976; 20:422-424.

20. Kobayashi Y, Horimoto T, Kawaoka Y, Alexander DJ, Itakura C. Pathological studies of chickens experimentally infected with two highly pathogenic avian influenza virus. Avian Pathol. 1996; 25:285-304.

21. Lamb RA, Krug RM. Orthomyxoviridae the virus and the replication. pp 1353-1395. In: Filelds Virology. Editors Fields, B.N., Knipe, D.M., Howly, P.M., Chanock, R.M., Melinick, J.L., Momth. T.P. and Roizman, B., 3rd ed. Lippincott-Raven, Philadelphia, Pa, 1996.

22. Lee MS, Chang PC, Shien JH, Cheng MC, Shieh SK, Identification and subtyping of avian influenza viruses by reverse transcription PCR. J. Virol. Meth. 2001; 97:13-22.

23. Liolios L, Jenney A, Spelman D, Kolsimbos T, Catton M, Wesselingh S. Comparison of a multiplex reverse transcription PCR-enzyme hybridization with conventional cell culture and immunofluorescence techniques for the detection of seven viral respiratory pathogens. J. Clin. Microbiol. 2001; 39:2779-2783.

24. Lipatov AS, Govorkova EA, Webby RG, Ozaki H, Peiris M, Guan Y. et al Influenza: Emergence and control. J. Virol. 2004; 78:8951-8959.

25. Mo IP, Brugh M, Fletcher OJ, Rowland GN, Swayne DE. Comparative pathology of chickens experimentally inoculated with avian influenza viruses of low and high pathogenicity. Avian Dis. 1997; 41:125-136.

26. Murphy BR, Webster RG. Orthomyxoviruses. In B.N. Fields, D.M. Knipe and P.M. Howley, Field Virology, 3rd ed. Lippincott-Raven, Philadelphia, 1996, pp.13971445.
27. Naeem K, Hussain M. An outbreak of avian influenza in poultry in Pakisthan. Vet. 1995; 137:439.

28. Newman J, Halvorson D, Karunakaran D, Poss P, Johnson J. Complication associated with avian influenza infections. Proceedings of the first international symposium on Avian Influenza. 1981. Richmond, U.S.A. Carter Comp. Corp, 1982, pp.8-12.

29. Nili H, Asasi K. Avian influenza (H9N2) outbreak in Iran. Avian Dis. 2002; 47:828-831.

30. Office International des Epizootics (OIE). 2004. Manual of diagnostic tests and vaccines for terrestrial animals. Highly pathogenic avian influenza. http//www.oie.int.int/eng/normes/manual/A_summary.ht $\mathrm{m}$.

31. Office International des Epizooties (OIE), Manual of diagnostic tests and vaccines for terrestrial animals. Highly Pathogenic Avian Influenza. Updated on 08.07.2005. OIE, Paris, France, 2005.

32. Peiris M, Yam WC, Chan KH, Ghose P, Shortridge KF. Influenza A H9N2: aspects of laboratory diagnosis. J. Clin. Microbiol. 1999; 37:3426-3427.

33. Rohm C, Zhou NA, Suss JC, Mackenzie J, Webster RG. Characterization of a novel influenza hemagglutinin H15: Criteria for determination of influenza A subtypes. Virol. 1996; 217:508-516.

34. Selleck PW, Lowther SL, Russell GM, Hooper PT. Rapid diagnosis of highly pathogenic avian influenza using pancreatic impression smears. Avian Dis. 2002; 47:1190.

35. Skeeles JK, Beasley JN, Blore P, Klopp S. Severe eggproduction drops in turkey breeders in South Central Missouri. Avian Dis. 1981; 25:764-767.

36. Suarez DL, Perdue ML, Cox N, Rowe T, Bender C, Huang J. et al. Comparisons of highly virulent H5N1 influenza A viruses isolated from humans and chickens from Hong Kong. J. Virol. 1998; 72:6678-6688.

37. Swayne DE. Pathobiology of H5N2 Mexican avian influenza virus infections of chickens. Vet. Pathol. 1997; 34:557-567.

38. Swayne DE, Slemons RD. Comparative pathology of a chicken-origin and two duck-origin influenza virus isolates in chickens: the effect of route inoculation. Vet Pathol. 1994; 31:237-245.

39. Webster RG. Influenza: an emerging disease. Emerg. Infect. Dis. 1998; 4:436-441.

40. Webster RG, Bean WJ, Gorman OT, Chamber TM, Kawaoka Y. Evolution and ecology of influenza A virus of seals. N. Engl. J. Med. 1992a; 304:91.

41. Webster RG, Bean WJ, Gorman OT, Chambers TM, Kawaoka Y. Evolution and ecology of influenza A viruses. Microbiol. Rev. 1992b; 56:152-179.

42. Webster RG, Schortidge KF, Kowaoka Y. Influenza interspecies transmission and emergence of new pandemics. FEMS Immunol. Med. Microbiol. 1997; 18: 275-279.

43. World Health Organization (WHO). WHO Manual on animal influenza diagnosis and surveillance. World Health Organization Geneva, 2002.

44. Yilmaz F, Timurkaan N, Coven F. Pathological Findings in Quails Infected with Avian Influenza A Virus H7 N1 Subtype. International J Poultry Sci. 2004; 3:764-767.

45. Ziegler T, Hall H, Sanchez-Favouier A, Ganble WC, Cox NJ. Type and subtype-specific detection of influenza viruses in clinical specimens by rapid cultures assay. J Clin. Microbiol. 1995; 33:318-321. 